\title{
Experimental Study
}

\section{Altered Perception of Distorted Visual Feedback Occurs Soon After Whiplash Injury: An Experimental Study of Central Nervous System Processing}

Liesbeth Daenen, PT, MSc ${ }^{1,2,3}$; Jo Nijs, PhD, $\mathrm{PT}^{3,4}$; Nathalie Roussel, PhD, $\mathrm{PT}^{3,4,5}$;

Kristien Wouters ${ }^{6}$; and Patrick Cras, MD, PhD ${ }^{1,2}$

From: ${ }^{1}$ Department of Neurology, Faculty of Medicine, University of Antwerp (UA), Belgium; 2Department of Neurology, Born-Bunge Institute and Antwerp University Hospital, Belgium; ${ }^{3}$ Chronic Pain and Chronic Fatigue Research Group (CHROPIVER), Department of Human Physiology, Faculty of Physical Education and Physiotherapy, Vrije Universiteit Brussel

(VUB), Belgium; ${ }^{4}$ Division of Musculoskeleta

Physiotherapy, Department of Health Sciences, University

College Antwerp (Artesis),

Belgium; ${ }^{5}$ Faculty of Medicine,

University of Antwerp (UA),

Belgium; ${ }^{6}$ Department of

Scientific Coordination and

Biostatistics, University

Hospital Antwerp (UZA), Belgium

Address correspondence: Jo Nijs, PhD

Vrije Universiteit Brussel, Building L-Mfys, Pleinlaan 2, BE-1050 Brussels, Belgium

E-mail: jo.nijs@vub.ac.be www.chropiver.be

Disclaimer: This study was financially supported by a grant (41/FAo2000o/3/3995) from the research council of

the University of Antwerp,

Belgium. No financial or other relationships could lead

to any conflict of interest.

Manuscript received: 04/10/2012

Revised manuscript received: 06/07/2012

Accepted for publication: 06/22/2012

Free full manuscript: www.painphysicianjournal.
Background: Sensory and motor system dysfunctions have been documented in a proportion of patients with acute whiplash associated disorders (WAD). Sensorimotor incongruence may occur and hence, may explain pain and other sensations in the acute stage after the trauma.

Objectives: The present study aimed at 1) evaluating whether a visually mediated incongruence between sensory feedback and motor output increases symptoms and triggers additional sensations in patients with acute WAD, 2) investigating whether the pattern of sensations in response to sensorimotor incongruence differs among patients suffering from acute and chronic WAD, and healthy controls.

\section{Study Design: Experimental study.}

Setting: Patients with acute WAD were recruited within one month after whiplash injury via the emergency department of a local Red Cross medical care unit, the Antwerp University Hospital, and through primary care practices. Patients with chronic WAD were recruited through an advertisement on the World Wide Web and from the medical database of a local Red Cross medical care unit. Healthy controls were recruited from among the university college staff, family members, and acquaintances of the researchers.

Methods: Thirty patients with acute WAD, 35 patients with chronic WAD, and 31 healthy persons were subjected to a coordination test. They performed congruent and incongruent arm movements while viewing a whiteboard or mirror.

Results. Twenty-eight patients with acute WAD reported sensations such as pain, tightness, feeling of peculiarity, and tiredness at some stage of the test protocol. No significant differences in frequencies and intensities of sensations were found between the various test stages $(P>.05)$. Significantly more sensations were reported during the incongruent mirror stage compared to the incongruent control stage $(P<.05)$. The pattern in intensity of sensations across the congruent and incongruent stages was significantly different between the WAD groups and the control group.

Limitations: The course and prognostic value of susceptibility to sensorimotor incongruence after an acute whiplash trauma are not yet clear from these results. A prospective longitudinal study with an expanded study population is needed to investigate if those with a lowered threshold to visually mediated sensorimotor incongruence in the acute stage are at risk to develop persistent pain and disability.

Conclusion: Patients with acute WAD present an exacerbation of symptoms and additional sensations in response to visually mediated changes during action. These results indicate an altered perception of distorted visual feedback and suggest altered central sensorimotor nervous system processing in patients with acute WAD.

Key words: Sensorimotor incongruence, visually mediated changes, whiplash, sensations, acute pain, chronic pain, altered central sensorimotor processing, central nervous system.

Pain Physician 2012; 15:-405-413 
W hiplash associated disorders (WAD) refer to the variety of clinical manifestations caused by a sudden accelerationdeceleration trauma. The clinical picture of WAD is heterogeneous and the recovery pathways are variable $(1,2)$. Most patients recover spontaneously within 3 months after the initial trauma. However, up to $50 \%$ of patients will continue to suffer from ongoing pain and disability one year after whiplash (3).

Chronic WAD have been associated with motor system dysfunctions, altered central pain processing, and psychosocial factors (e.g., posttraumatic stress, depression, and pain catastrophizing) (4-14). From previous research, it is known that cervical motor dysfunction is of limited prognostic value and cannot explain the complex clinical picture of chronic $\operatorname{WAD}(13,15)$.

A growing body of research has revealed the involvement of the central nervous system in the maintenance of symptoms after a whiplash trauma. Widespread hyperalgesia and impaired endogenous analgesia, indicative for altered central pain processing and central sensitization, were observed in patients with chronic WAD $(9-11,16)$. Furthermore, we recently found that visually mediated changes between sensory feedback and motor output exacerbate symptoms and provoke additional sensations in those suffering from chronic WAD (17). These results suggest altered sensorimotor central nervous processing in chronic WAD (17).

The role of cortical mechanisms in the origin of pain has been postulated. Disturbances in sensory and motor system function may induce sensorimotor incongruence and hence, produce pain and other sensations (18-20) similar to incongruence between visual and vestibular input that cause motion sickness (21-23). There is evidence that distorting visual feedback of a moving limb aggravates pain and other symptoms in patients with chronic pain $(17,24,25)$.

In contrast to the expanding knowledge of underlying mechanisms in chronic WAD, the acute stage of the injury has been largely unexplored. Nevertheless, disturbances in sensory and motor system function have been documented in patients with acute WAD (7,26-30). Widespread hyperalgesia was observed soon after injury in those with persistent moderate/severe symptoms at 6 months and was associated with poor functional recovery $(13,15,28)$. Furthermore, disturbances in motor system function were found early after the trauma $(7,26,29,30)$.

Given the evidence for sensorimotor system dysfunction in some patients with acute WAD, sensorimo- tor incongruence may occur, and hence, may explain pain and other sensations in the acute stage. However, the role of sensorimotor incongruence has not been studied soon after whiplash injury

Improved insight into the acute stage of the condition may help in identifying those at risk of developing persistent pain and disability. In turn, this may lead to improved intervention strategies to prevent the transition from acute to chronic WAD.

For the reasons outlined above, the present study aimed at evaluating whether a visually mediated incongruence between sensory feedback and motor output increases symptoms and triggers additional sensations in patients soon after whiplash trauma. A second aim was to investigate whether the pattern of sensations in response to sensorimotor incongruence differs between patients suffering from acute and chronic WAD, and healthy controls.

\section{Methods}

\section{Study Design}

A cross-sectional study design was used to evaluate whether patients with acute WAD are susceptible to visually mediated sensorimotor incongruence

\section{Patients}

Patients with acute WAD were recruited within one month after experiencing whiplash via the emergency department of a local Red Cross medical care unit, the Antwerp University Hospital, and primary care practices. Patients with chronic WAD were recruited through advertisements on the World Wide Web and from the medical database of a local Red Cross medical care unit. Chronicity was defined as complaints persisting for at least 3 months. A variety of recruitment procedures were used in order to prevent recruitment bias (31). The inclusion criteria for the acute and chronic WAD groups were currently having symptoms resulting from a whiplash trauma and fulfilling the diagnostic criteria of WAD grade I to III as defined by the Quebec Task Force classification (32). Patients were excluded if they were classified as WAD grade IV (32) and if they reported a previous history of whiplash trauma.

Healthy controls were recruited among the university college staff, family members, and acquaintances of the researchers. Controls were not allowed to participate if they ever had experienced a whiplash trauma, suffered from (persistent) pain or neck-shoulder-arm symptoms, or had sought medical help for neck-shoul- 
der-arm symptoms in the previous 6 months.

Patients were asked to discontinue analgesic and anti-inflammatory drugs 48 hours before testing. This duration was chosen based on ethical consideration and because analgesic effects are mostly limited in time (33). They were instructed to avoid physical exertion and refrain from consuming nicotine, alcohol, and caffeine 24 hours before testing. Patients were excluded if they were pregnant, or if they suffered from any cardiovascular or neurological disease.

The sample size was based on the power calculation in our previous work (17).

\section{Procedure}

Before participating, patients carefully read an information leaflet. In the leaflet, they were informed that the experiment would consist of a coordination task with both arms. No further explanation concerning the task was given and no association with pain and other sensations was made. Written informed consent was obtained from all patients before testing in accordance with the Declaration of Helsinki. The study was approved by the Human Research Ethics Committee of the Antwerp University Hospital. A standardized questionnaire was used to collect personal characteristics as well as accident-related and health-related information. The WAD groups filled in the Neck Disability Index (NDI). Next, they were subjected to a coordination task simulating incongruence between sensory feedback and motor output.

\section{Measurements}

\section{Self-Reported Questionnaire}

The NDI (score out of 100) is a reliable and valid self-reported measure $(34,35)$ frequently used in WAD studies.

\section{Bimanual Coordination Test}

The assessment apparatus and procedure employed in the current study have been described in detail by McCabe and colleagues $(20,36)$ and were used in our previous studies $(17,37)$. The method is briefly explained here. For details, the reader is referred to the previous studies $(17,37)$.

The assessment apparatus, consisting of a mirror (intervention side) and a whiteboard (control side), was positioned on the patient's anterior midline. They were asked to flex/extend both arms in a congruent/incongruent manner while viewing the whiteboard/mirror and attending to a reference point (a horizontal line at the level of the subject's umbilicus). At the end of each stage, 2 open-ended questions were asked: "How did it feel?" and "Were you aware of any changes in either limb?" To prevent introducing bias, no further explanation was given and no suggestions with regard to sensations were made. In case of reported sensations, the intensity was rated on a numerical rating scale from 0 to 10 (38). If sensations were reported, a rest period was introduced until the symptoms had disappeared or returned to their baseline status.

Experiencing pain at the time of testing is likely to introduce bias into the study. Therefore control conditions (i.e., flex/extend both arms in a congruent/incongruent manner without viewing the whiteboard/ mirror) were included and patients were compared with controls. All the limb assessments were executed consecutively and in random order. The abbreviations for the test and control stages that will be used in the rest of this article are: congruent whiteboard $=\mathrm{CW}$; incongruent whiteboard = IW; congruent mirror = $\mathrm{CM}$; incongruent mirror = IM; congruent control = CC; incongruent control $=\mathrm{IC}$.

\section{Statistical Methods}

Statistical analyses were conducted using SPSS 18.0 for Windows (SPSS Inc., Chicago, IL). Normality of the variables was tested with the Kolmogorov-Smirnov test. Comparability of the groups for gender distribution, education level and age was verified with Pearson's $\chi 2$ test and independent-sample t-test. A McNemar test (binomial distribution) was used to compare the frequencies of sensations within the congruent (i.e., CW and CM) and incongruent test stages (i.e., IW and IM) and between the test and control stages in the acute WAD group. A Wilcoxon signed rank test was used to compare the intensities of sensations across the various stages in the acute WAD group. Two repeated measures of analysis of covariances (ANOVAs) were conducted to evaluate the pattern of sensations across the control, whiteboard, and mirror condition within the acute WAD, chronic WAD, and control group and among the different groups while performing congruent and incongruent movements respectively. Each model had one between patients factor - group (acute WAD, chronic WAD, controls) and one within patients factor - stage (control, whiteboard, mirror). Post-hoc Bonferroni correction was performed in case of significant factors. Since the gender distribution was significantly different between the acute WAD group and the 
chronic WAD and control groups, gender was added as a covariate in both repeated measures ANOVAs. If no sensations were reported during an individual stage, the frequency and intensity score was counted as "0" and that score was recorded for statistical analysis. The significance level was set at .05 .

\section{Results}

\section{Participants}

Thirty patients with acute WAD (14 women and 16 men), 35 patients with chronic WAD (26 women and 9 men) and 31 healthy controls ( 24 women and 7 men) volunteered for the study. The mean age was 43.30 ( \pm $10.98)$ years for the acute WAD, 43.80 ( \pm 9.59$)$ years for the chronic WAD and $43.19( \pm 16.11)$ years for the control group. The 3 groups were comparable for age $(P>.05)$. The chronic WAD and control groups were comparable for gender distribution and education level $(P>$.05). The acute WAD group differed in gender distribution and education level compared to the other groups $(P<.05)$. The mean score of the NDI was 32.30 $( \pm 14.84)$ in the acute WAD group and $44.36( \pm 12.64)$ in the chronic WAD group. Details of the NDI classification of the WAD groups are presented in Table 1.

\section{Reported sensations in response to the various stages in patients with acute WAD}

Twenty-eight (93\%) patients reported sensations at some stage of the test protocol (i.e., upon perform- ing the coordination test with both arms in a congruent and incongruent manner viewing the whiteboard or the mirror), which were increased compared to those experienced at baseline within one month after the whiplash trauma. The frequencies of sensations across the various test stages are presented in the upper row of Table 2. No significant differences in frequencies of sensations were found between the various test stages (i.e., between the $\mathrm{CW}$ and $\mathrm{CM}$ stage and between the IW and IM stage, $P>$.05).

The patients described sensations as pain (43\%), tightness $(37 \%)$, feeling of peculiarity $(37 \%)$, tiredness $(27 \%)$, weight changes $(20 \%)$, loss of control (17\%), perceived loss/additional arm (10\%), dizziness $(7 \%)$, tingling $(7 \%)$, nausea $(7 \%)$, and discomfort (3\%).

The intensities of the reported sensations are presented in the lower row of Table 2. Comparing the median intensities of reported sensations between the various test stages (i.e., between the $\mathrm{CW}$ and $\mathrm{CM}$ stage and between the IW and IM stage), no significant differences were found ( $P>$.05; data of Wilcoxon signed rank tests not shown).

When performing the coordination test in a congruent and incongruent manner without viewing the whiteboard or mirror (the control stages), 21 (70\%) patients reported pain, (43\%) tightness (27\%) and/or tiredness (13\%). The frequencies and intensities of sensations during the control stages are presented in the right columns of Table 2 .

Table 1. The NDI classification of the patients with acute WAD $(n=30)$ and chronic WAD $(n=35)$

\begin{tabular}{|c|c|c|c|}
\hline & NDI < 8 & NDI 10 - 28 & NDI >30 \\
\hline Acute WAD (frequency) & 1 & 12 & 17 \\
\hline Chronic WAD (frequency) & 0 & 1 & 34 \\
\hline
\end{tabular}

NDI = Neck Disability Index; NDI < 8 = minor symptoms; NDI $10-28$ = mild pain and disability; $>30$ NDI = moderate/severe pain and disability

Table 2. Frequency and intensity of reported sensations per stage of the coordination test in patients with acute WAD $(n=30)$.

\begin{tabular}{|l|c|c|c|c|c|c|c|c|c||}
\hline & CW & CM & p & IW & IM & p & CC & IC \\
\hline Frequency (\%) & $25(83)$ & $26(87)$ & 1.000 & $25(83)$ & $27(90)$ & .500 & $21(70)$ & $20(67)$ \\
\hline Intensity \\
\hline $\begin{array}{l}\text { Median (IQR) } \\
\text { Mean (SD) }\end{array}$ & $\begin{array}{c}5(3) \\
4.03(2.44)\end{array}$ & $\begin{array}{c}5(3) \\
4.33(2.31)\end{array}$ & .720 & $\begin{array}{c}4(4) \\
3.87(2.42)\end{array}$ & $\begin{array}{c}4(3) \\
4.20(2.33)\end{array}$ & .695 & $\begin{array}{c}3(5) \\
2.80(2.28)\end{array}$ & $\begin{array}{c}3(4) \\
2.43(2.21)\end{array}$ \\
\hline
\end{tabular}

$\mathrm{CW}=$ Congruent whiteboard stage; $\mathrm{CM}=$ Congruent mirror stage; $\mathrm{IW}=$ Incongruent whiteboard stage; $\mathrm{IM}=$ Incongruent mirror stage; $\mathrm{CC}=$ Congruent control stage; IC = Incongruent control stage; $\mathrm{SD}=$ Standard deviation; IQR = Interquartile range

Significant at $\mathrm{p}<.05$ 
Significantly more patients with acute WAD reported sensations during the IM stage compared to the IC stage ( $P<.05$; data of McNemar test not shown). No significant differences were observed between the other control and test stages; i.e., between the CC and CW stages, between the CC and CM stages, and between the IC and IW stages $P>$.05; data of McNemar tests not shown). The median intensities of reported sensations were significantly different among the control and the various test stages $(P<.05$; data of Wilcoxon signed rank tests not shown).

The results of reported sensations during the performance of the coordination test in patients with chronic WAD and healthy controls are described elsewhere (17).

\section{Pattern of sensations during performance of the coordination test in patients with acute WAD, chronic WAD, and healthy controls}

\section{Congruent stages}

Figure 1 shows the pattern in intensity of sensations across the $C C, C W$ and $C M$ stages in the acute WAD, chronic WAD, and control groups. The results re- vealed a significant stage $(F=39.396, d f=1.811, P<$ $.001)$ and group effect $(\mathrm{F}=55.642, \mathrm{df}=2, P<.001)$, and a significant stage $x$ group interaction $(F=7.412, \mathrm{df}=$ 3.622, $P<.001)$. Since the Mauchly's test of sphericity was significant $(1<.05)$, Greenhouse-Geisser was used for stage effect and stage $x$ group interaction. The post hoc analyses revealed a significant difference in the pattern of sensations between the control group and both WAD groups $(P<.001)$. No significant difference was observed between the acute WAD and the chronic WAD groups $(P>.05)$. Gender had no significant effect on the pattern of sensations across the congruent stages $(P>.05)$.

\section{Incongruent stages}

Figure 2 presents the pattern in intensity of sensations across the IC, IW, and IM stages in the acute WAD, chronic WAD, and control groups. The results indicated a significant stage effect $(F=50.012, \mathrm{df}=2, P<.001)$ and group effect $(F=36.874$, df $=2, P<.001)$, and a significant stage $x$ group interaction $(F=2.718, \mathrm{df}=$ $4, P=.031)$. Since the Mauchly's test of sphericity was significant $(P<.05)$, Greenhouse-Geisser was used for stage effect and stage $x$ group interaction. The post

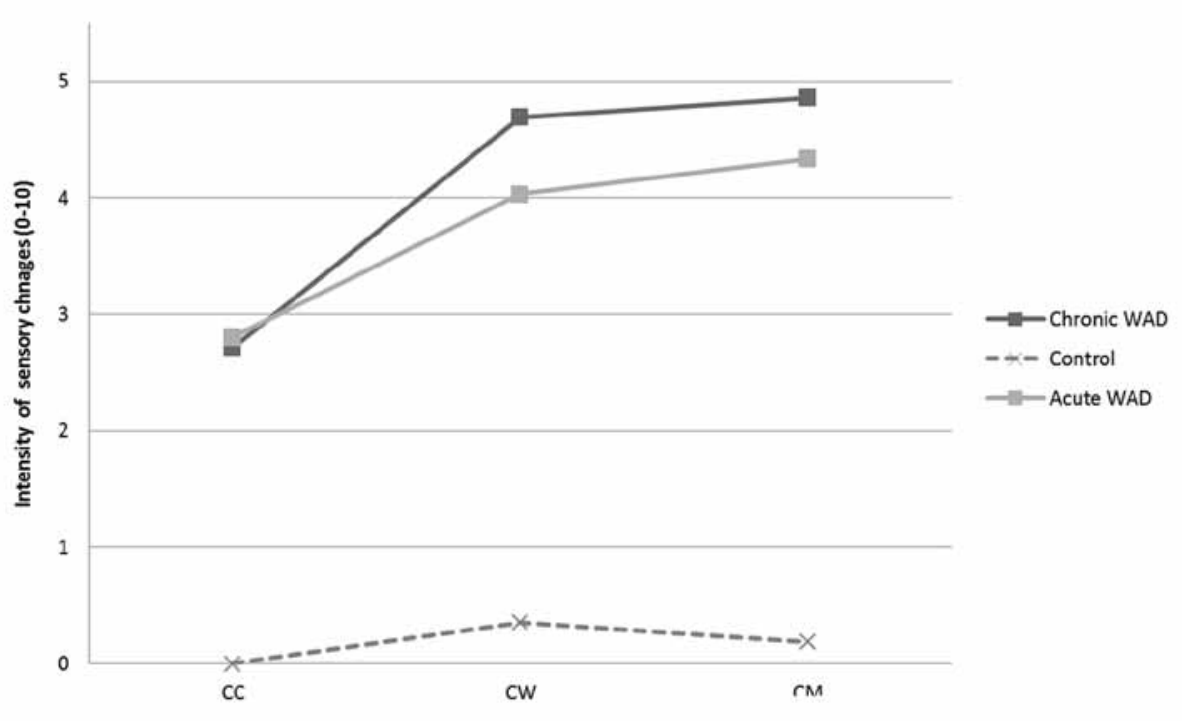

Fig. 1: Evolution of sensory changes during performance of the coordination test in a congruent manner in patients with acute WAD $(n=30)$, chronic WAD $(n=35)$ and healthy controls $(n=31)$. WAD: whiplash associated disorders; CC: moving both arms in a congruent manner without viewing the whiteboard or mirror; $C W$ : moving both arms in a congruent manner while viewing the whiteboard; CM: moving both arms in a congruent manner while viewing the mirror. 


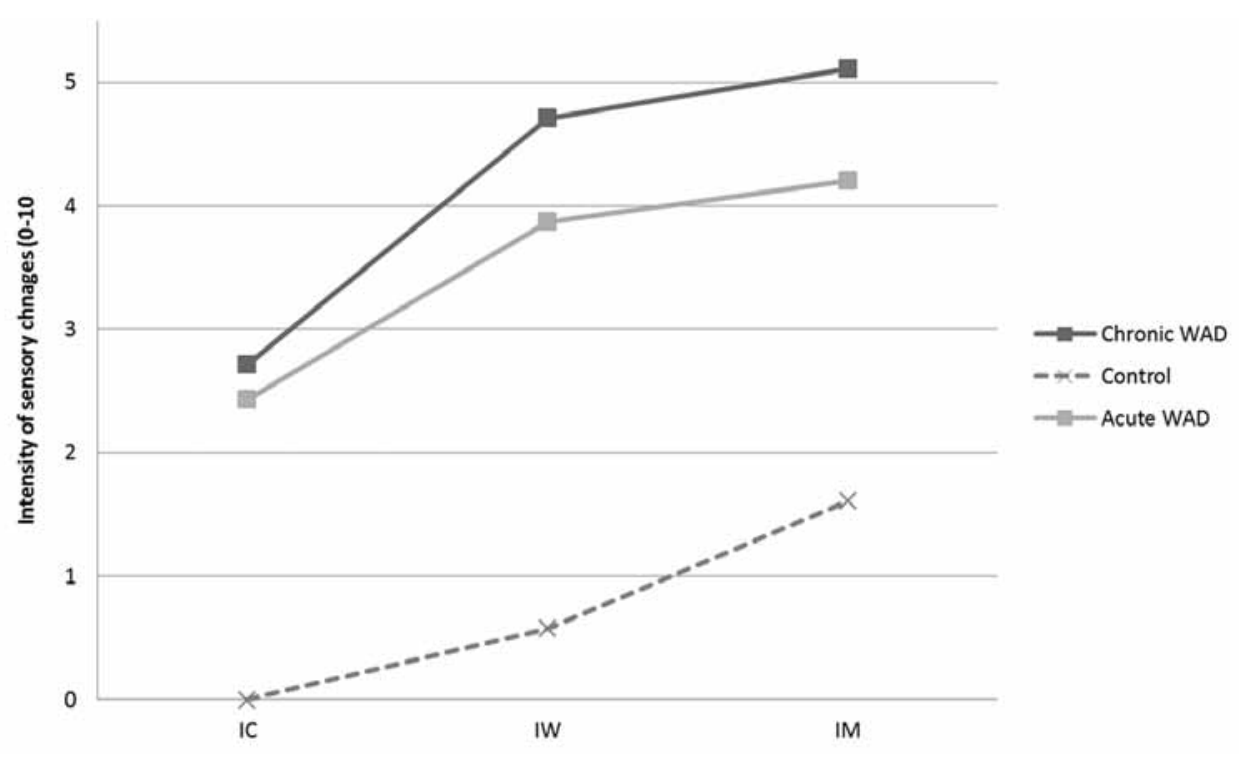

Fig. 2: Evolution of sensations during performance of the coordination test in an incongruent manner in patients with acute WAD $(n=30)$, chronic WAD $(n=35)$ and controls $(n=31)$.

WAD: Whiplash associated disorders; IC: moving both arms in an incongruent manner without viewing the whiteboard or mirror; $I W$ : moving both arms in an incongruent manner while viewing the whiteboard; IM: moving both arms in an incongruent manner while viewing the mirror.

hoc analyses revealed a significant difference in the pattern of sensations between the control group and both WAD groups $(P<.001)$. No significant difference was observed between the acute WAD and the chronic WAD groups $(P>.05)$. The pattern of sensations across the incongruent stages was not influenced by gender $(P>.05)$.

\section{Discussion}

Little is known about the acute stage of WAD. The results of the present study provide the first evidence that visually mediated changes between motor output and sensory feedback exacerbate symptoms and provoke additional sensations within one month after a whiplash injury.

The pattern of sensations was significantly different between the WAD groups and the control group during the congruent as well as the incongruent stages.

\section{Reported sensations in response to various stages}

In order to ensure the smoothness of motor actions and maintain a constant update on the interaction be- tween motor and sensory systems, the predicted motor output is continuously compared to the actual sensory feedback by the brain. Accordingly, the motor plan will be adjusted and appropriate compensation strategies will be used in order to achieve the goal. These processes, mediated by the motor control system, are considered to be implicit and automatic. But in cases of conflict between the predicted and current motor plan, the implicit sensorimotor integration processes fail and the conscious mode is invoked. As result, the individual becomes aware of the conflicting information processing $(19,39,40)$.

There is growing evidence that incongruence between sensory feedback and motor output may cause pain and other sensations (17-20,36,37). An induced sensorimotor conflict, by using a similar optokinetic system (whiteboard/mirror) as in the present study, may generate sensations such as loss of control, feeling of peculiarity, weight changes, and discomfort in healthy individuals $(17,36)$. The maximum frequency of sensations was reported during the stage with the highest level of incongruence (i.e., the IM stage) $(17,36)$. 
This contrasts to the findings observed in patients suffering from acute WAD showing no differences in frequencies and intensities of sensations between the various test stages. Reducing or disturbing the visual input of a moving limb (via using a mirror or a nonreflective whiteboard) seems to be sufficient to exacerbate symptoms in the acute stage after the whiplash trauma. This points toward a lowered threshold for visually mediated changes between sensory feedback and motor output in patients suffering from acute WAD.

In concordance with these findings, no differences in the frequencies of sensations were observed among the various test stages in patients with chronic WAD either (17). Based on the results of the former and latter studies, we suggest that the clinical picture of WAD is a presentation of sensorimotor incongruence caused by disturbances in sensory and motor system function. This could explain why patients with WAD experience an exacerbation of symptoms when the incongruence increases (through hiding a moving limb or distorting visual feedback). These results are indicative of an altered perception of distorted visual feedback and changes in sensorimotor central nervous processing in patients with WAD.

The notion that cortical mechanisms are involved in the origin of pain is substantiated by the results of neuroimaging studies. Several brain regions, including the primary and secondary somatosensory cortices, the insula, the anterior cingulate cortex, the amygdala, the prefrontal cortex, and the thalamus are activated during pain perception (41). Acute experimental pain can cause functional reorganization of the somatosensory cortex (42), and brain processing differs between acute and chronic pain. In chronic pain, the somatosensory cortex is subjected to neuronal plasticity. Changes in sensorimotor areas have been documented in a variety of chronic pain conditions such as phantom limb pain, chronic low back pain, and complex regional pain syndrome (43-45). This sensorimotor remapping may corrupt the motor output and hence, provoke incongruence between predicted and actual sensory feedback. Inducing sensorimotor incongruence, through distorting visual feedback of a moving limb, can worsen pain and other sensations in patients with fibromyalgia, complex regional pain syndrome, and chronic WAD $(17,20,25)$.

Due to peripheral sensitization, which is a normal protective mechanism preventing use and further damage of injured regions, the afferent input may increase in the acute stage after whiplash trauma. As a result, changes in cortical organization of the somatosensory cortex may occur and may influence processing in other brain areas. This could signal incongruence between sensory feedback and motor output. If this incongruence between sensory input and motor output persists and the extent exceeds the individual threshold, pain and other sensations may be generated explaining the exacerbation of pain and other symptoms during the performance of the test stages in the acute WAD group.

In contrast, no significant differences in frequency of sensations were observed between the congruent test and control stages and between the IW and IC stages. Only during the IM stage (i.e., the stage with the highest level of incongruence) did the acute WAD group report significantly more sensations compared to the IC stage. However, reducing the visual input of a moving limb (via using a whiteboard) seems to be sufficient to exacerbate symptoms, yet insufficient to increase the frequency of sensations. Further, the frequencies and intensities of sensations were not different between the various test stages in the acute stage after injury. This could be explained by the heterogeneity of the acute WAD group.

While the current study demonstrated that susceptibility to visually mediated changes between sensory feedback and motor output occurs soon after whiplash trauma, the course and prognostic value of this susceptibility to sensorimotor incongruence is not yet clear. This may be an interesting issue for further research. It is possible that these changes, suggestive of altered sensorimotor central nervous processing, occur only in a subgroup of patients with acute WAD. A prospective longitudinal study with an expanded study population is needed to investigate if those with a lowered threshold to visually mediated sensorimotor incongruence in the acute stage are at risk to develop persistent pain and disability. It is likely that these disturbances in sensorimotor central nervous processing occur within one month of injury and persist in those who develop ongoing pain and disability. Our previous work in chronic WAD supports this hypothesis; the patients with chronic WAD included in this study mostly suffered from moderate/severe pain and disability (17).

In addition, there is evidence of generalized hypersensitivity indicating changes in central pain processing soon after injury in patients with persistent moderate/ severe symptoms at 6 months after whiplash injury (28). These disturbances in central sensory system function may be associated with sensorimotor incongruence. It will be interesting to explore if those patients who dis- 
play changes in the central mediation of pain also demonstrate disturbances in central sensorimotor nervous processing. Further studies should examine whether these changes underlie 2 distinctive mechanisms or are part of the same underlying mechanism.

\section{Pattern of sensations in patients with acute and chronic WAD and controls}

The evolution in intensity of sensations was significantly different between the WAD and control groups during the congruent as well as the incongruent stages. Across the congruent stages, there was a rising curve for both WAD groups and a flat curve for the control group. Across the incongruent stages, the rising curve in intensity of sensations was also found for the control group. However, the location of increase was different among the groups. In the control group the strongest increase was observed between the IW and IM stages, while in both WAD groups the strongest increase was found between the control and whiteboard stages. These results indicate vulnerability to distorting the visual feedback of a moving limb in patients with acute as well as chronic WAD. The effects remain even when gender was put in the model as a covariate. Gender had no effect on the pattern of sensations in response to sensorimotor incongruence.

\section{Conclusion}

In conclusion, patients with acute WAD present an exacerbation of symptoms and additional sensations in response to visually mediated changes during action. These results indicate an altered perception of distorted visual feedback and suggest altered central nervous system processing in patients with acute WAD. Further research is needed to investigate whether these changes occur in a subgroup of patients with acute WAD who develop chronic pain and disability.

\section{Acknowledgements}

The authors are grateful to Bonny Raadsen and Leonie Van Zweden for assisting during the data collection.

\section{Funding}

This study was financially supported by a grant (41/ FA020000/3/3995) from the research council of the University of Antwerp, Belgium.

\section{References}

1. Kamper, S, Rebbeck, T, Maher, C, McAuley, J, Sterling, M. Course and prognostic factors of whiplash: a systematic review and meta-analysis. Pain 2008; 138(3):617629.

2. Walton, D, Pretty, J, Macdermid, J, Teasell, R. Risk factors for persistent problems following whiplash injury: results of a systematic review and meta-analysis. J Orthop Sports Phys Ther 2009; 39(5):344350.

3. Carroll, L, Holm, L, Hogg-Johnson, S, Côté, P, Cassidy, J, Haldeman, S, Nordin, M, Hurwitz, E, Carragee, E, van der Velde, G, Peloso, P, Guzman, J. Course and prognostic factors for neck pain in whiplash-associated disorders (WAD): results of the Bone and Joint Decade 2000-2010 Task Force on Neck Pain and Its Associated Disorders. Spine (Phila Pa 1976) 2008; 33(4 Suppl):S83-92.

4. Falla, D, Bilenkij, G, Jull, G. Patients with chronic neck pain demonstrate altered patterns of muscle activation during performance of a functional upper limb task. Spine (Phila Pa 1976) 2004;
29(13):1436-1440.

Kristjansson, E, Dall'Alba, P, Jull, G. A study of five cervicocephalic relocation tests in three different subject groups. Clin rehabil 2003; 17(7):768-774.

6. Nederhand, MJ, Hermens, HJ, MJ, IJ, Turk, DC, Zilvold, G. Cervical muscle dysfunction in chronic whiplash-associated disorder grade 2: the relevance of the trauma. Spine (Phila Pa 1976) 2002; 27(10):1056-1061.

Sterling, M, Jull, G, Vicenzino, B, Kenardy, J, Darnell, R. Development of motor system dysfunction following whiplash injury. Pain 2003; 103(1-2):65-73.

8. Woodhouse, A, Vasseljen, O. Altered motor control patterns in whiplash and chronic neck pain. BMC Musculoskel Dis 2008; 9:90.

9. Banic, B, Petersen-Felix, S, Andersen, O, Radanov, B, Villiger, P, Arendt-Nielsen, L, Curatolo, M. Evidence for spinal cord hypersensitivity in chronic pain after whiplash injury and in fibromyalgia. Pain 2004; 107:7-15.
10. Curatolo, M, Petersen-Felix, S, ArendtNielsen, L, Giani, C, Zbinden, A, Radanov, B. Central Hypersensitivity in Chronic Pain After Whiplash Injury. Clin J Pain 2001; 17:306-315.

11. Scott, D, Jull, G, Sterling, M. Widespread sensory hypersensitivity is a feature of chronic whiplash-associated disorder but not chronic idiopathic neck pain. Clin J pain 2005; 21(2):175-181.

12. Carroll, LJ, Cassidy, JD, Cote, P. Frequency, timing, and course of depressive symptomatology after whiplash. spine 2006; 31(16): E551-556.

13. Sterling, M, Jull, G, Kenardy, J. Physical and psychological factors maintain long-term predictive capacity postwhiplash injury. Pain 2006; 122(1-2):102108.

14. Thompson, DP, Oldham, JA, Urmston, M, Woby, SR. Cognitive determinants of pain and disability in patients with chronic whiplash-associated disorder: a cross-sectional observational study. Physiotherapy 2010; 96(2):151-159.

15. Sterling, M, Jull, G, Vicenzino, B, Kenar- 
dy, J, Darnell, R. Physical and psychological factors predict outcome following whiplash injury. Pain 2005; 114(1-2):141148.

16. Van Oosterwijck, J, Nijs, J, Meeus, M, Van Loo, M, Paul, L. Lack of Endogenous Pain Inhibition During Exercise in People With Chronic Whiplash Associated Disorders: An Experimental Study. J Pain 2012; 13(3):242-254.

17. Daenen, L, Nijs, J, Roussel, N, Wouters, K, Van Loo, M, Cras, P. Sensorimotor Incongruence Exacerbates Symptoms in Patients with Chronic Whiplash Associated Disorders: An Experimental Study. Rheumatology 2012a; 51(8):1492-1499.

18. Harris, A). Cortical origin of pathological pain. Lancet 1999; 354(9188):1464-1466.

19. McCabe, CS, Blake, DR. Evidence for a mismatch between the brain's movement control system and sensory system as an explanation for some pain-related disorders. Curr Pain Headache Rep 2007; 11(2):104-108.

20. McCabe, CS, Cohen, H, Blake, DR. Somaesthetic disturbances in fibromyalgia are exaggerated by sensory motor conflict: implications for chronicity of the disease? Rheumatology (Oxford) 2007; 46(10):1587-1592.

21. Reason, JT. Motion sickness adaptation: a neural mismatch model. ] Roy Soc Med 1978; 71(11):819-829.

22. Warwick-Evans, LA, Symons, N, Fitch, $\mathrm{T}$, Burrows, L. Evaluating sensory conflict and postural instability. Theories of motion sickness. Brain res bull 1998; $47(5): 465-469$.

23. Watt, DG. Sensory and motor conflict in motion sickness. Brain Behav Evol 1983; 23(1-2):32-35.

24. McCabe, CS, Cohen, H, Blake, DR. Somaesthetic disturbances in fibromyalgia are exaggerated by sensory motor conflict: implications for chronicity of the disease? Rheumatology (Oxford) 2007; 46(10):1587-1592.

25. Moseley, GL, Parsons, TJ, Spence, C. Visual distortion of a limb modulates the pain and swelling evoked by movement. Curr Biol 2008; 18(22):R1047-1048.

26. Kasch, H, Stengaard-Pedersen, K, Arendt-Nielsen, L, Staehelin Jensen, T. Headache, neck pain, and neck mobility after acute whiplash injury: a prospective study. Spine (Phila Pa 1976) 2001; 26(11):1246-1251.

27. Kasch, H, Stengaard-Pedersen, K, Arendt-Nielsen, L, Staehelin Jensen, T. Pain thresholds and tenderness in neck and head following acute whiplash injury: a prospective study. Cephalalgia 2001; 21(3):189-197.

28. Sterling, M, Jull, G, Vicenzino, B, Kenardy, J. Sensory hypersensitivity occurs soon after whiplash injury and is associated with poor recovery. Pain 2003; 104:509-517.

29. Sterling, M, Jull, G, Vicenzino, B, Kenardy, J. Characterization of acute whiplash-associated disorders. Spine (Phila Pa 1976) 2004; 29(2):182-188.

30. Nederhand, MJ, Hermens, HJ, MJ, IJ, Turk, DC, Zilvold, G. Chronic neck pain disability due to an acute whiplash injury. Pain 2003; 102(1-2):63-71.

31. Nijs, J, Inghelbrecht, E, Daenen, L, Hachimi-Idrissi, S, Hens, L, Willems, B, Roussel, N, Cras, P, Wouters, K, Bernheim, J. Recruitment bias in chronic pain research: whiplash as a model. Clin Rheumatol 2011; 30:1481-1489.

32. Spitzer, W, Skovron, M, Salmi, L, Cassidy, J, Duranceau, J, Suissa, S, Zeiss, E. Scientific monograph of Quebec Task Force on whiplash associated disorders: redefining 'Whiplash' and its management. Spine (Phila Pa 1976) 1995; 20:1-73.

33. Meeus, M, Nijs, J, Van de Wauwer, N, Toeback, L, Truijen, S. Diffuse noxious inhibitory control is delayed in chronic fatigue syndrome: an experimental study. Pain 2008; 139(2):439-448.

34. Jorritsma Wim, de Vries Grietje E, Geertzen Jan H.B., Dijkstra Pieter U, F, RM. Neck Pain and Disability Scale and the Neck Disability Index: reproducibility of the Dutch Language Versions. Eur
Spine ] 2010; 19:1695-1701.

35. Vernon, H, Mior, S. The neck disability index: a study of reliability and validity.] Manip Physiol Ther 1991; 14:409-415.

36. McCabe, CS, Haigh, RC, Halligan, PW, Blake, DR. Simulating sensory-motor incongruence in healthy volunteers: implications for a cortical model of pain. Rheumatology 2005; 44(4):509-516.

37. Daenen, L, Roussel, N, Cras, P, Nijs, J. Sensorimotor incongruence triggers sensory disturbances in professional violinists: an experimental study. Rheumatology 2010; 49(7):1281-1289

$38 . \quad$ Likert, R. A technique for the development of attitude scales. Educ Psychol Meas 1952; 12:313-315.

39. Frith, CD, SJ, B, DM, W. Abnormalities in the awareness and control of action. Phil Trans R Soc Lond 2000; (355):17711788.

40. Wolpert, DM, Ghahramani, Z, Jordan, MI. An internal model for sensorimotor integration. Science 1995; 269(5232):18801882.

41. May, A. Neuroimaging: visualising the brain in pain. Neurol Sci 2007; 28 Suppl 2:S101-107.

42. Soros, P, Knecht, S, Bantel, C, Imai, T, Wusten, R, Pantev, C, Lutkenhoner, B, Burkle, $H$, Henningsen, $H$. Functional reorganization of the human primary somatosensory cortex after acute pain demonstrated by magnetoencephalography. Neurosci lett 2001; 298(3):195-198.

43. Maihofner, C, Handwerker, HO, Neundorfer, B, Birklein, F. Patterns of cortical reorganization in complex regional pain syndrome. Neurology 2003; 61(12):17071715 .

44. Flor, H, Braun, C, Elbert, T, Birbaumer, N. Extensive reorganization of primary somatosensory cortex in chronic back pain patients. Neurosci lett 1997; 224(1):58.

45. Flor, $\mathrm{H}$, Nikolajsen, L, Staehelin Jensen, T. Phantom limb pain: a case of maladaptive CNS plasticity? Nat Rev Neurosci 2006; 7(11):873-881. 
